Research Paper

\title{
Falls rate increase and foot dorsal flexion limitations are exhibited in patients who suffer from asthma: A novel case-control study
}

\author{
César Calvo-Loboํㅜ, Roi Painceira-Villar², Vanesa García-Paz³, Ricardo Becerro-de-Bengoa-Vallejo4, Marta \\ Elena Losa-Iglesias 5 , Pedro V. Munuera-Martínez ${ }^{\natural}{ }^{\bowtie}$, Daniel López-López² \\ 1. Nursing and Physical Therapy Department, Institute of Biomedicine (IBIOMED), Faculty of Health Sciences, Universidad de León, Ponferrada, León, Spain. \\ 2. Research, Health and Podiatry Unit. Department of Health Sciences. Faculty of Nursing and Podiatry. Universidade da Coruña, Spain. \\ 3. Departament of Allergology. Complexo Hospitalario Universitario de Ferrol, Ferrol. Spain \\ 4. Facultad de Enfermería, Fisioterapia y Podología. Universidad Complutense de Madrid, Madrid, Spain \\ 5. Faculty of Health Sciences. Universidad Rey Juan Carlos, Alcorcón, Spain. \\ 6. Department of Podiatry. University of Seville, Spain. \\ $\square$ Corresponding author: Pedro V. Munuera Martínez, PhD, MSc, DP. Podiatry Department, Universidad de Sevilla, C/ Avicena, s/n. 41009 Sevilla, telephone \\ 954486526 / 954482170 (ibercom 86526 / 82170), fax 954482171, email: pmunuera@us.es. https://orcid.org/0000-0001-5708-4178 \\ (c) Ivyspring International Publisher. This is an open access article distributed under the terms of the Creative Commons Attribution (CC BY-NC) license \\ (https://creativecommons.org/licenses/by-nc/4.0/). See http://ivyspring.com/terms for full terms and conditions.
}

Received: 2018.12.08; Accepted: 2019.03.27; Published: 2019.04.25

\begin{abstract}
Purpose: Based on the possible association between reduced foot dorsiflexion and high risk of falls, the main objective was to determine the ankle and $1^{\circ}$ metatarsophalangeal joint ( 1 stMTTP) dorsiflexion range of motion and falls rate in patients with asthma compared to healthy matched-paired controls.

Methods: A case-control study was carried out. Eighty participants were recruited and divided into patients with asthma (case group; $n=40$ ) and matched-paired healthy participants (control group; $n=40$ ). Foot dorsal flexion range of motion (assessed by the Weight-Bearing Lunge Test [WBLT]) and falls rate (evaluated as falls number during the prior year) were considered as the primary outcomes. Indeed, ankle dorsiflexion was measured by a mobile app $\left(^{\circ}\right)$ and a tape measure $(\mathrm{cm})$ as well as 1 stMTTP dorsiflexion was determined by and universal goniometer $\left({ }^{\circ}\right)$.

Results: Statistically significant differences $(P<.05)$ showed that patients with asthma presented a greater falls rate than healthy participants and reduced bilateral ankle and 1stMTTP dorsiflexion ranges of motion than healthy participants, except for the left ankle dorsiflexion measured as degrees $(P>.05)$.

Conclusions: These study findings showed that a falls rate increase and bilateral foot dorsal flexion limitations of the ankle and IstMTTP joints are exhibited in patients who suffer from asthma.
\end{abstract}

Key words: accidental falls, ankle joint, asthma, hallux, range of motion, articular, spirometry

\section{Introduction}

Asthma may be considered as one of the most frequent chronic inflammatory diseases associated to an airways impairment which may worldwide affect up to 300 million individuals [1]. Patients who suffer from asthma seem to present poor quality of life [2], depression and anxiety [3], as well as social, behavioral, and psychological well-being (4). Thus, further studies are necessary in order to control the asthma status and its consequences related to physical and psychological aspects [2].

Regarding the physical assessment of patients with asthma, spirometry parameters seem to be commonly used in order to evaluate the airways alterations [5]. Indeed, the forced expiratory volume in one second $\left(\mathrm{FEV}_{1}\right)$, forced vital capacity $(\mathrm{FVC})$ and $\mathrm{FEV}_{1} / \mathrm{FVC}$ relationship seem to be commonly considered as the most used spirometry parameters to predict physiological measurements in patients with asthma [6].

In addition, thoracic mobility has been evaluated as an important physical measurement in patients who suffer from asthma [7]. Asthmatic patients seem 
to present forwarded head and shoulders posture, reduced chest wall expansion, limited internal rotation of shoulders and reduced thoracic spine flexibility compared to non-asthmatic individuals [8]. Despite there is a clear temporomandibular and neck range of motion limitation in asthmatic patients [9], there is a lack of knowledge addressing the existence of mobility alterations in the lower limbs from patients diagnosed with this condition.

Older adults who suffered from asthma seemed to present a high falls rate similar to older adults who suffered from chronic obstructive pulmonary disease [10]. Nevertheless, there is a lack of studies comparing both patients with asthma and healthy subjects in the general population. In addition, foot dorsal flexion limitations, such as ankle and $1^{\circ}$ metatarsophalangeal joint ( $1^{\text {st }}$ MTTP), may increase the lack of coordination [11] and falls risk [12], being an excellent predictor for ambulation loss [13].

Recently, respiratory parameters alterations, such as reduced diaphragm contractility, have been related to chronic ankle instability [14]. This association may suggest the presence of spirometry alterations [5,6] and high risk of falls [10] in patients with asthma. Consequently, it is plausible the existence of a relationship between respiratory muscles contractibility impairment and ankle instability [14] with reduced foot dorsiflexion range of motion and high risk of falls [11-13]. Therefore, we hypothesize that patients with asthma will show a reduced foot dorsal flexion range of motion and a greater falls rate with respect to healthy subjects. Thus, the main objective of this research was to determine the ankle and $1^{\text {st }}$ MTTP dorsiflexion range of motion and falls rate compared to healthy matched-paired controls. In addition, the second aims were to compare the kinesiophobia and spirometry parameters between patients with asthma and healthy participants.

\section{Materials and Methods}

\section{Study design}

This study was a case-control study in order to compare the foot dorsiflexion range of motion and the falls rate between patients who suffered from asthma and healthy controls. According to this design and the guidelines for reporting observational studies, The Strengthening the Reporting of Observational Studies in Epidemiology (STROBE) statement were followed [15].

\section{Ethical statement}

This study was approved by the ethics committee of the Universidade da Coruña (Spain). All participants signed the informed consent inform before their inclusion in the present research. In addition, the Helsinki declaration as well as all national and international ethical standards for human experimentation were respected $[16,17]$.

\section{Sample size calculation}

The sample size calculation was performed by means of the between-two-groups differences for independent samples by the software of $G^{*}$ Power (version 3.1.9.2) and based on the ankle dorsal flexion $\left({ }^{\circ}\right)$ during the Weight-Bearing Lunge Test (WBLT) of a pilot study $(\mathrm{n}=30)$ with 2 groups (mean $\pm \mathrm{SD}), 15$ patients with asthma (case group; $43.64 \pm 5.42^{\circ}$ ) and 15 healthy matched-paired participants (control group, $\left.47.02 \pm 4.70^{\circ}\right)$. In addition, 2-tailed hypothesis, effect size of 0.66 , a-error probability of 0.05 , power (1- $\beta$ error probability) of 0.80 as well as allocation ratio $(\mathrm{N} 2 / \mathrm{N} 1)$ of 1 were applied for the sample size determination. Therefore, a total sample size of 74 participants, 37 patients with asthma and 37 healthy matched-paired controls, was calculated.

\section{Participants}

Participants were recruited by a consecutive sampling method from the Conplexo Hospitalario de Ferrol and an outpatient clinic (A Coruña, Spain). Considering the inclusion criteria, participants from 18 to 65 years old who signed the informed consent, were non- smokers and did not receive any anti-allergic immunotherapy intervention were included in the study. For the case group, patients diagnosed with asthma or allergic asthma by the same experienced allergist doctor were considered if they presented the clinical symptomatology of asthma, a positive lung function bronchodilator test with a $\mathrm{FEV}_{1}$ $>12 \%$ and $200 \mathrm{ml}$ with respect to the baseline values $[5,6]$. For the control group, healthy matched-paired participants were included. Regarding exclusion criteria, the participants with the following features were excluded: age younger than 18 years old or older than 65 years old, not sign the informed consent, active smokers, undergoing allergy immunotherapy, reduced ambulation, systemic diseases, neuropathy, musculoskeletal disorders, fractures, psychiatric illnesses and/or neoplasia (malignant tumors) [18].

\section{Descriptive data}

Quantitative descriptive data such as age (years), weight $(\mathrm{kg})$, height $(\mathrm{m})$, body mass index (BMI; calculated by the Quetelet index as $\mathrm{kg} / \mathrm{m}^{2}$ ) [19], and physical activity assessed by the International Physical Activity Questionnaire (IPAQ; measured as metabolic equivalent index per minutes per week [METS/min/week]), which was validated into Spanish with an excellent reliability (intraclass correlation coefficient [ICC] $=0.93]$ [20] 
Categorical data such as professional activity student (student, freeland, employed, unemployed or retired), civil status (single, divorced, widowed, couple or married), sex (male or female), plantar orthosis (yes or no), and physical activity levels (divided into "low" with less than 600 METS, "moderate" from 600 to 3000 METS, and "vigorous" with more than 3000 METS according to the IPAQ) were collected [20].

\section{Outcome measurements}

Foot dorsal flexion range of motion and falls rate were considered as the primary outcomes. In addition, the secondary outcomes were kinesiophobia and spirometry parameters.

\section{Foot dorsal flexion range of motion}

Ankle and 1 1'MTTP joints dorsal flexion range of motion was measured by an experienced podiatrist. The Weight-Bearing Lunge Test (WBLT) was applied in order to quantify and evaluate the ankle dorsiflexion, which has shown to be a valid tool with an excellent inter-rater reliability for angle (ICC = 0.97 ) and distance $(\mathrm{ICC}=0.99)$ measurements [21-23]. Indeed, the TiltMeter (IntegraSoftHN - Carlos E. Hernández Pérez) free mobile app on an Apple iPhone was use to carry out the measurement of the degrees $\left(^{\circ}\right)$ of movement, which has shown an excellent inter-rater reliability $(\mathrm{ICC}=0.96)$ and an appropriate concurrent validity (ICC $=0.83$ ) with an inclinometer [24]. In addition, a tape measure was applied to measure the distance $(\mathrm{cm})$ from the most distal area of the foot to the wall. To carry out this measurement, the patient was placed on top of the measuring tape with the foot perpendicular to a wall, moving it sequentially $(1 \mathrm{~cm}$ further from the wall each time) until reaching the maximum ankle dorsal flexion without lifting the heel from the floor. The distance from the foot to the wall was measured with a tape measure, and the angle from the tibia axis in reference to the wall was assessed with the app sensor placed on the tibia anterior tuberosity [21-25].

An analogue universal goniometer was used to quantify the WBLT forced dorsal flexion of the hallux

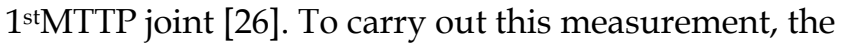
patient was asked for slightly forwarding the foot, maintaining a normal walking angle. The fixed arm of the goniometer was placed on the diaphysis of the $1^{\text {st }}$ metatarsal bone and the mobile arm was placed on the $1^{\text {st }}$ phalanx bone at the medial side of the hallux. The measurement was performed after a hallux forced dorsiflexion. This procedure has shown an adequate validity with radiographic range of motion and an excellent inter-rater reliability (ICC $=0.87-0.95$ ) for hallux 1 ${ }^{\text {st } M T T P ~ d o r s i f l e x i o n ~ m e a s u r e m e n t ~[27] . ~}$

\section{Falls rate}

Fall rate was measured as the number of falls self-reported by the participants during the prior year. Falls rate has been previously measured in older adults who suffered from chronic obstructive pulmonary disease and asthma [10].

\section{Kinesiophobia}

The Tampa Scale of Kinesiophobia - 11 items (TSK-11) was used to determine the fear of movement and self-reported by the participants. This tool was validated into Spanish and presented a two-factor structure (activity avoidance and harm) with a scored system by a 4 points Likert scale (from 11 to 44 points; greater scores suggested an increased fear of movement) (28). An adequate internal consistency (Cronbach's $a=0.78$ ) and high test-retest reliability $(\mathrm{ICC}=0.82)[29-32]$.

\section{Spirometry parameters}

Spirometry parameters were evaluated by an experienced allergist doctor in order to evaluate the airways alterations by means of the Datospir 600 Touch device (SIBELMED e-20 software) [5]. Indeed, the $\mathrm{FEV}_{1}, \mathrm{FVC}$ and $\mathrm{FEV}_{1} / \mathrm{FVC}$ values (\%) were recorded due to these parameters may be considered as the most useful spirometry parameters in order to predict physiological measurements in patients who suffered from asthma [6]. These parameters addressing the lung function have been well correlated $(r=0.747)$ to chest wall expansion [33]. In addition, spirometry parameters have shown a good reliability (ICC $=0.786-0.929)$ [34].

\section{Statistical analysis}

Statistical analyses were carried out by means the of the software of SPSS 24.0v (IBM for Windows; Armonk, NY: IBM Corp.) using an a error of 0.05 in conjunction with a $95 \%$ confidence interval (CI).

For quantitative data, Kolmogorov-Smirnov test was applied to evaluate normality. All data were described as mean \pm standard deviation (SD) and range (minimum-maximum) due to median \pm interquartile range did not reflect accurately the differences for some non-parametric data. For parametric data (Kolmogorov-Smirnov $P$-value $\geq .05$ ), between-groups differences were analyzed by Student $t$ tests for independent samples. For non-parametric data (Kolmogorov-Smirnov $P$-value < $.05)$, between-groups differences were analyzed by Mann-Whitney $U$ tests for independent samples. In addition, bars graphs were added to illustrate the comparisons of fall rate and WBLT foot dorsiflexion range of motion means (including 95\% CI error bars) between the patients with asthma and healthy 
matched-paired controls.

For categorical data, frequencies as well as percentages were applied to describe these values and their between-groups differences were analyzed by Fisher exact tests and Chi-square $\left(\chi^{2}\right)$ tests.

\section{Results}

\section{Descriptive data}

A total sample of 80 participants was recruited and divided into patients with asthma (case group; $\mathrm{n}$ $=40)$ and matched-paired healthy participants (control group; $\mathrm{n}=40$ ) with an age range from 19 to 65 years old. The sample comprised 30 (37.5\%) males and $50(62.5 \%)$ females. There were not any statistically significant differences $(P>.05)$ between both groups for all descriptive data. Table 1 and 2 showed the quantitative and categorical descriptive data of the sample, respectively.

\section{Outcome measurements between asthma vs healthy participants}

The outcome measurements between patients diagnosed with asthma and healthy matched-paired controls were shown in Table 3 . Regarding falls rate and kinesiophobia, statistically significant differences
$(P<.05)$ showed that patients with asthma presented a greater falls rate than healthy participants during the prior year (Figure 1), but not for kinesiophobia $(P$ $>$.05). Considering the foot dorsiflexion (Figures 2 and 3), statistically significant differences $(P<.05)$ showed that patients with asthma presented bilaterally lower ankle and $1^{\text {st }}$ MTTP dorsiflexion range of motion than healthy participants, except for the left ankle dorsiflexion $(P>$.05). For the spirometry parameters, there were statistically significant differences $(P>.05)$ for the $\mathrm{FEV}_{1} / \mathrm{FVC}$ parameter with lower values in the asthma group compared to the control group, but not for $\mathrm{FEV}_{1}$ and FVC separately.

\section{Discussion}

To the authors' knowledge, this is the first study that shows new evidence about the falls rate increase and foot dorsal flexion limitations in patients with asthma compared to healthy matched-paired participants. These associations may be a key focus in order to develop new intervention strategies for falls prevention in patients with asthma, due to a high falls prevalence, similar to patients with chronic obstructive pulmonary disease, was shown in patients who suffer from asthma [10].

Table 1. Quantitative descriptive data of the patients with asthma and healthy matched-paired controls.

\begin{tabular}{llll}
\hline Quantitative descriptive data & $\begin{array}{l}\text { Total group }(\mathbf{n}=\mathbf{8 0}) \\
\text { Mean } \pm \text { SD (Range) }\end{array}$ & $\begin{array}{l}\text { Asthma }(\mathbf{n}=40) \\
\text { Mean } \pm \text { SD (Range) }\end{array}$ & $\begin{array}{l}\text { Healthy (n= 40) } \\
\text { Mean } \pm \text { SD (Range) }\end{array}$ \\
\hline Age (years) & $40.02 \pm 12.98(19-65)$ & $38.10 \pm 12.84(20-65)$ & $41.95 \pm 12.99(19-65)$ \\
Weight $(\mathrm{kg})$ & $72.05 \pm 14.69(47-120)$ & $71.72 \pm 16.55(48-120)$ & $72.37 \pm 17.75(47-96)$ \\
Height $(\mathrm{m})$ & $1.66 \pm 0.09(1.50-1.97)$ & $1.67 \pm 0.10(1.53-1.97)$ & $1.66 \pm 0.09(1.50-1.87)$ \\
BMI $\left(\mathrm{kg} / \mathrm{m}^{2}\right)$ & $25.78 \pm 4.32(18.41-39.18)$ & $25.38 \pm 4.43(18.41-39.18)$ & $26.17 \pm 4.24(18.83-34.72)$ \\
IPAQ (METS/min/week) & $3297.59 \pm 3559.41(0-15918)$ & $2679.45 \pm 3300.59(0-15918)$ & $3915.73 \pm 3739.78(0-15243)$ \\
\hline
\end{tabular}

Abbreviations: BMI, body mass index; IPAQ, International Physical Activity Questionnaire; METs, metabolic equivalent index per week. * Student's $t$-test for independent samples was applied. † Mann-Whitney $U$ test was used. In all the analyses, $P<.05$ (with a $95 \%$ confidence interval) was considered statistically significant.

Table 2. Categorical descriptive data of the patients with asthma and healthy matched-paired controls.

\begin{tabular}{|c|c|c|c|c|c|}
\hline \multicolumn{2}{|c|}{ Categorical descriptive data } & Total group $(\mathrm{n}=80)$ & Asthma $(n=40)$ & Healthy $(n=40)$ & $P$ Value \\
\hline \multirow[t]{5}{*}{ Professional activity } & student & $13(16.2 \%)$ & $7(17.5 \%)$ & $6(15 \%)$ & $.516 \ddagger$ \\
\hline & freeland & $10(12.5 \%)$ & $6(15 \%)$ & $4(10 \%)$ & \\
\hline & employed & $43(53.7 \%)$ & $20(50 \%)$ & $23(57.5 \%)$ & \\
\hline & unemployed & $7(8.8 \%)$ & $2(5 \%)$ & $5(12.5 \%)$ & \\
\hline & retired & $7(8.8 \%)$ & $5(12.5 \%)$ & $2(5 \%)$ & \\
\hline \multirow[t]{5}{*}{ Civil status } & single & $19(23.7 \%)$ & $9(22.5 \%)$ & $10(25 \%)$ & $.973 \ddagger$ \\
\hline & divorced & $4(5 \%)$ & $2(5 \%)$ & $2(5 \%)$ & \\
\hline & widowed & $0(0 \%)$ & $0(0 \%)$ & $0(0 \%)$ & \\
\hline & couple & $11(13.7 \%)$ & $5(12.5 \%)$ & $6(15 \%)$ & \\
\hline & married & $46(57.6 \%)$ & $24(60 \%)$ & $22(55 \%)$ & \\
\hline \multirow[t]{3}{*}{ IPAQ category* } & low & $19(23.7 \%)$ & $13(32.5 \%)$ & $6(15 \%)$ & $.175 \ddagger$ \\
\hline & moderate & $37(46.3 \%)$ & $17(42.5 \%)$ & $20(50 \%)$ & \\
\hline & vigorous & $24(30 \%)$ & $10(25 \%)$ & $14(35 \%)$ & \\
\hline \multirow[t]{2}{*}{ Sex } & Male & $30(37.5 \%)$ & $14(35 \%)$ & $16(0 \%)$ & $.818 \dagger$ \\
\hline & Female & $50(62.5 \%)$ & $26(65 \%)$ & $24(60 \%)$ & \\
\hline \multirow[t]{2}{*}{ Plantar orthosis } & Yes & $7(8.7 \%)$ & $4(10 \%)$ & $3(7.5 \%)$ & $1.000 \dagger$ \\
\hline & No & $73(91.3 \%)$ & $36(90 \%)$ & $37(92.5 \%)$ & \\
\hline
\end{tabular}

Abbreviations: METs, metabolic equivalent index per week; IPAQ, International Physical Activity Questionnaire. $\ddagger$ Frequency, percentage $(\%)$ and Chi-squared test $\left(\mathrm{x}^{2}\right)$ were utilized. †Frequency, percentage (\%) and Fisher exact test $\left(\chi^{2}\right)$ were utilized. *Physical activity levels were divided into "low" with less than 600 METS, "moderate" from 600 to 3000 METS, and "vigorous" with more than 3000 METS according to the IPAQ. In all the analyses, $P<.05$ (with a $95 \%$ confidence interval) was considered statistically significant. 
Table 3. Comparisons of outcome measurements between the patients with asthma and healthy matched-paired controls

\begin{tabular}{|c|c|c|c|c|}
\hline Outcome measurements & $\begin{array}{l}\text { Total group }(n=80) \\
\text { Mean } \pm \text { SD (Range) }\end{array}$ & $\begin{array}{l}\text { Asthma }(n=40) \\
\text { Mean } \pm \text { SD (Range) }\end{array}$ & $\begin{array}{l}\text { Healthy }(n=40) \\
\text { Mean } \pm \text { SD (Range) }\end{array}$ & $\begin{array}{l}P \text {-Value asthma } \\
\text { vs healthy }\end{array}$ \\
\hline Falls rate (n during 1 year) & $0.47 \pm 1.22(0-6)$ & $0.70 \pm 1.45(0-6)$ & $0.25 \pm 0.89(0-5)$ & $.049 \dagger$ \\
\hline Kinesiophobia (TSK-11) & $21.70 \pm 6.21(11-38)$ & $22.07 \pm 6.59(11-38)$ & $21.32 \pm 5.87(11-34)$ & $.593^{*}$ \\
\hline Right ankle dorsiflexion $\left({ }^{\circ} \mathrm{WBLT}\right)$ & $45.05 \pm 5.52(31.80-60.10)$ & $43.74 \pm 4.87(35.80-56.80)$ & $46.36 \pm 5.87(31.80-60.10)$ & $.033^{*}$ \\
\hline Right ankle dorsiflexion (cm WBLT) & $10.21 \pm 2.83(3-17)$ & $9.50 \pm 2.96(3-16)$ & $10.92 \pm 2.52(7-17)$ & $.035 \dagger$ \\
\hline Left ankle dorsiflexion $\left({ }^{\circ} \mathrm{WBLT}\right)$ & $44.58 \pm 6.06(19.60-60.30)$ & $43.54 \pm 4.84(33.20-55.40)$ & $45.62 \pm 2.98(19.60-60.30)$ & $.127^{*}$ \\
\hline Left ankle dorsiflexion (cm WBLT) & $10.43 \pm 2.75(3-17)$ & $9.75 \pm 2.88(3-15)$ & $11.12 \pm 2.48(7-17)$ & $.046 \dagger$ \\
\hline Right $1^{\circ} \mathrm{MTTP}$ dorsiflexion $\left({ }^{\circ} \mathrm{WBLT}\right)$ & $34.86 \pm 16.87(4-70)$ & $30.75 \pm 16.52(4-70)$ & $38.97 \pm 16.41(8-68)$ & $.027 \dagger$ \\
\hline Left $1^{\circ} \mathrm{MTTP}$ dorsiflexion $\left({ }^{\circ} \mathrm{WBLT}\right)$ & $32.81 \pm 17.89(6-69)$ & $28.62 \pm 17.71(6-69)$ & $37.00 \pm 17.27(8-68)$ & $.027 \dagger$ \\
\hline FVC $(\%)$ & $95.73 \pm 9.95(64-118)$ & $95.82 \pm 10.88(64-113)$ & $95.65 \pm 9.06(80-118)$ & $.938^{*}$ \\
\hline $\mathrm{FEV}_{1}(\%)$ & $99.42 \pm 10.90(61-122)$ & $98.05 \pm 12.73(61-121)$ & $100.80 \pm 8.65(84-122)$ & $.263^{*}$ \\
\hline $\mathrm{FEV}_{1} / \mathrm{FVC}(\%)$ & $104.13 \pm 7.18(89-123)$ & $102.10 \pm 7.69(89-122)$ & $106.17 \pm 6.07(94-123)$ & $.010^{*}$ \\
\hline
\end{tabular}

Abbreviations: IR, interquartile range; $\mathrm{FEV}_{1}$, forced expiratory volume in one second; FHSQ, Foot Health Status Questionnaire; FVC, forced vital capacity; MTTP, metatarsophalangeal joint; TSK-11, Tampa Scale of Kinesiophobia - 11 items; WBLT, Weight-Bearing Lunge Test. *Student's $t$-test for independent samples was used. $†$ Mann-Whitney $\mathrm{U}$ test was used. In all the analyses, $P<.05$ (with a $95 \%$ confidence interval) was considered statistically significant (bold).

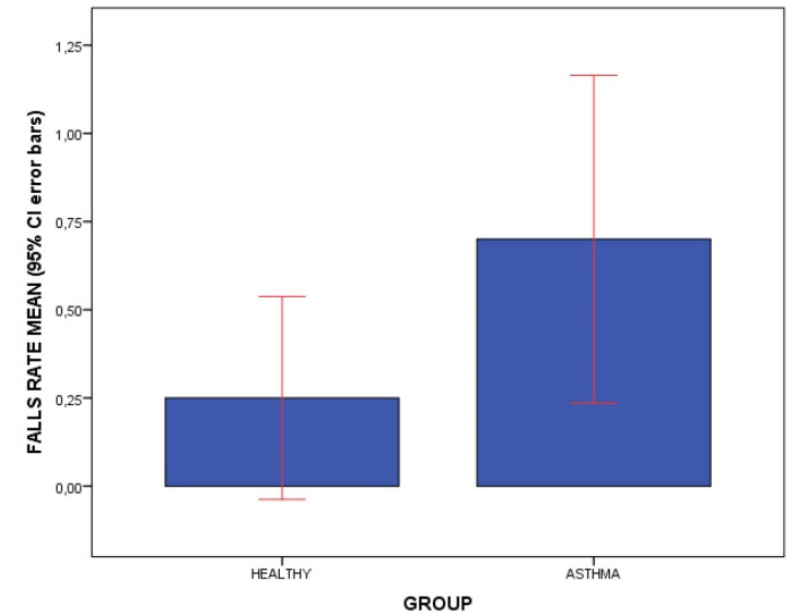

Figure 1. Bars graph to illustrate the comparisons of fall rate means (including $95 \% \mathrm{Cl}$ error bars) between the patients with asthma and healthy matched-paired controls. Abbreviations: $\mathrm{Cl}$, confidence interval.

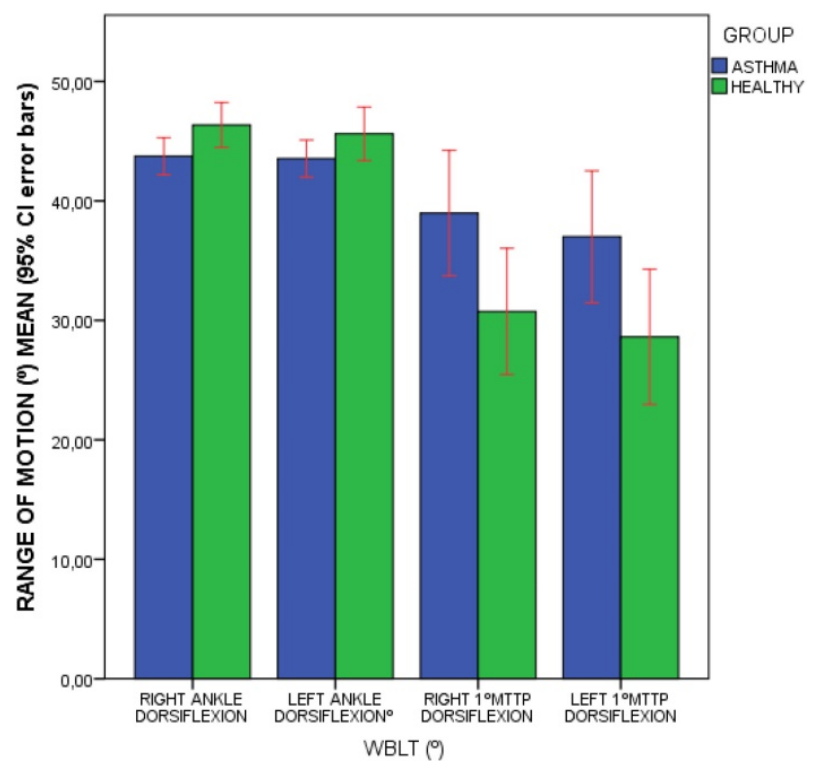

Figure 2. Bars graph to illustrate the comparisons of WBLT foot dorsiflexion range of motion $\left(^{\circ}\right.$ ) means (including $95 \% \mathrm{Cl}$ error bars) between the patients with asthma and healthy matched-paired controls. Abbreviations: $1^{\circ}$ MTTP, $1^{\circ}$ metatarsophalangeal joint; $\mathrm{Cl}$, confidence interval, WBLT, Weight-Bearing Lunge Test.

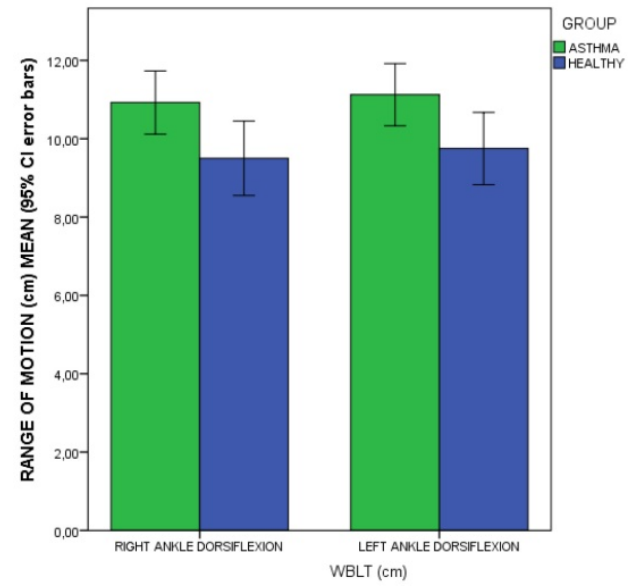

Figure 3. Bars graph to illustrate the comparisons of WBLT ankle dorsiflexion range of motion $(\mathrm{cm})$ means (including $95 \% \mathrm{Cl}$ error bars) between the patients with asthma and healthy matched-paired controls. Abbreviations: $\mathrm{Cl}$, confidence interval, WBLT, Weight-Bearing Lunge Test.

\section{Primary outcomes}

Our findings suggesting a falls rate increase and reduced foot dorsiflexion may be partially explained due to the respiratory muscles may be related to postural control stability, which may be frequently altered in patients with asthma, and the diaphragm contractility was previously associated to chronic ankle instability $[8,14,35]$. Spirometry alterations associated to asthma may influence a high risk of falls in older adults $[5,6,10]$ and this risk may be increased by the reduced foot dorsal flexion range of motion in accordance with our results in the general population [11-13]. Some common activities in daily life, such as descending stairs, walking or kneeling, need at least $10^{\circ}$ of ankle dorsal flexion, while some activities such as running need from $20^{\circ}$ to $30^{\circ}$ of dorsiflexion range of motion [25]. According to Table 3 and Figure 2, our results showed that ankle dorsiflexion range of motion in patients with asthma (varied from $43.54 \pm$ $4.84^{\circ}$ to $43.74 \pm 4.87^{\circ}$ ) and healthy controls (varied from $45.62 \pm 2.98^{\circ}$ to $46.36 \pm 5.87^{\circ}$ ) was higher than these cut off values and would not influence the daily 
life activities. Dorsiflexion of the $1^{\text {st }}$ MTTP joint (from $45^{\circ}$ to $65^{\circ}$ ) during the gait cycle propulsive phase may be important for an efficient foot function [26]. According to Table 3 and Figure 3, our findings showed more than $10^{\circ}$ of the hallux $1^{\text {st MTTP joint }}$ dorsiflexion limitation in patients with asthma (from $28.62 \pm 17.71^{\circ}$ to $30.75 \pm 16.52^{\circ}$ ) with respect to healthy participants (from $37.00 \pm 17.27^{\circ}$ to $38.97 \pm 16.41^{\circ}$ ) and this difference could impair the foot function during the gait cycle. Nevertheless, future studies evaluating the gait cycle between patients diagnosed with asthma and healthy participants should be performed.

Regarding our initial hypothesis, patients with asthma seem to present a reduced foot dorsal flexion range of motion and a greater falls rate with respect to healthy subjects. These associations could be due to patients with asthma present respiratory alterations $[5,6]$, including a reduced diaphragm contractility which have been linked to chronic ankle instability [14] and consequently high risk of falls [10]. Indeed, a recent study has shown the presence of higher mechanosensitivity in the tarsal tunnel of patients with asthma with respect to healthy controls [36]. According to this study, the sensitization of the soft tissues of the tarsal tunnel, including the plantar flexor tendons, blood vessels and tibial nerve, could decrease foot dorsiflexion range of motion and stability.

\section{Secondary outcomes}

Kinesiophobia did not seem to be related with asthma diagnosis due to possibly fear of movement appears frequently in patients with pain or injuries [28-32] and these conditions were excluded from our study. Regarding the lung function, spirometry parameters showed a reduced $\mathrm{FEV}_{1} / \mathrm{FVC}$ coefficient in patients with asthma with respect to healthy participants in accordance with the physiological changes and airways impairments reported in prior studies of patients with asthma $[5,6]$.

\section{Future studies and clinical implications}

Future randomized controlled clinical trials applying therapeutic interventions for increasing ankle dorsiflexion, such as joint mobilization, stretching techniques, local vibration therapy, hyperbaric oxygen intervention and electrical stimulation physical therapies as well as mental-relaxation psychological interventions should be carried out [37]. In addition, postural motor control exercises should be evaluated in patients with asthma due to the existent relationship between respiratory muscle contractility and ankle instability as possible influencers of falls [14].

\section{Limitations}

Some limitation should be considered in the present study. First, a consecutive sampling method was used in order to recruit participants and should be considered in future studies. Second, the age range from our sample only comprised participants from 19 to 65 years old, but older adults age range should be included in future studies due to a high risk of falls rate has been concretely shown in older adults with asthma [10]. Third, chest expansion measurements were not included in the present study, but lung function parameters were evaluated and present a good correlation with chest wall expansion [33]. Finally, future studies should introduce a scale specifically investigating falls or balance assessment scale like the Berg Balance Scale [38].

\section{Conclusions}

These study findings showed that a falls rate increase and bilateral foot dorsal flexion limitations of the ankle and 1stMTTP joints are exhibited in patients who suffer from asthma.

\section{Acknowledgements}

Conceptualization, CCL, RPV and DLL.; Methodology, CCL, RPV, DLL, VGP, RBBV, MELI and PMM; Software, RPV and VGP.; Validation, CCL, RPV, DLL, VGP, RBBV, MELI and PMM; Formal Analysis, CCL, DLL, RBBV and MELI; Investigation, CCL, RPV, DLL, VGP, RBBV, MELI and PMM; Resources, CCL, RPV, DLL, VGP, RBBV, MELI and PMM; Data Curation, CCL, RPV, DLL and VGP; Writing - Original Draft Preparation, CCL, DLL, RBBV, MELI and PMM; Writing - Review \& Editing, CCL, RPV, DLL, VGP, RBBV, MELI and PMM; Visualization, CCL, RPV, DLL and VGP.; Supervision, CCL, DLL, RBBV, MELI and PMM.

\section{Competing Interests}

The authors have declared that no competing interest exists.

\section{References}

1. Masoli M, Fabian D, Holt S, Beasley R, Global Initiative for Asthma (GINA) Program. The global burden of asthma: executive summary of the GINA Dissemination Committee report. Allergy. 2004;59(5):469-78. Available from: http://doi.wiley.com/10.1111/j.1398-9995.2004.00526.x

2. Banjari M, Kano Y, Almadani S, Basakran A, Al-Hindi M, Alahmadi T. The Relation between Asthma Control and Quality of Life in Children. Int J Pediatr. 2018;2018:1-6. Available from: http://www.ncbi.nlm.nih.gov/ pubmed/30057631

3. Coban H, Aydemir Y. The relationship between allergy and asthma control, quality of life, and emotional status in patients with asthma: a cross-sectional study. Allergy Asthma Clin Immunol. 2014;10(1):67. Available from: http://aacijournal.biomedcentral.com/articles/10.1186/s13223-014-0067-4

4. Al-Khateeb AJ, Al Khateeb JM. Research on psychosocial aspects of asthma in the Arab world: a literature review. Multidiscip Respir Med. 2015;10(1):15. Available from: http://www.mrmjournal.com/content/10/1/15

5. Carpenter DM, Jurdi R, Roberts CA, Hernandez M, Horne R, Chan A. A Review of Portable Electronic Spirometers: Implications for Asthma 
Self-Management. Curr Allergy Asthma Rep. 2018;18(10):53. Available from: http://www.ncbi.nlm.nih.gov/pubmed/30145683

6. Sharan R V, Abeyratne UR, Swarnkar VR, Claxton S, Hukins C, Porter P. Predicting spirometry readings using cough sound features and regression. Physiol Meas. 2018;39(9):095001. Available from: http://www.ncbi.nlm.nih. gov/pubmed/30091716

7. Serrano-villar Y, Rodríguez-grande E. Thoracic index in adults with asthma: a study of validity and reliability. Chiropr Man Therap. 2018;26(1):18. Available from: http://www.ncbi.nlm.nih.gov/pubmed/29850018

8. Lunardi AC, Marques da Silva CCB, Rodrigues Mendes FA, Marques AP, Stelmach R, Fernandes Carvalho CR. Musculoskeletal Dysfunction and Pain in Adults with Asthma. J Asthma. 2011;48(1):105-10. Available from: http:// www.ncbi.nlm.nih.gov/pubmed/21189115

9. Chaves TC, Grossi DB, de Oliveira AS, Bertolli F, Holtz A, Costa D. Correlation between signs of temporomandibular (TMD) and cervical spine (CSD) disorders in asthmatic children. J Clin Pediatr Dent. 2005;29(4):287-92. Available from: http://www.ncbi.nlm.nih.gov/pubmed/16161392

10. Bozek A, Jarzab J, Hadas E, Jakalski M, Canonica GW. Fall episodes in elderly patients with asthma and COPD - a pilot study. J Asthma. 2018;1-14. Available from: http://www.ncbi.nlm.nih.gov/pubmed/29738272

11. Yingyongyudha A, Saengsirisuwan V, Panichaporn W, Boonsinsukh R. The Mini-Balance Evaluation Systems Test (Mini-BESTest) Demonstrates Higher Accuracy in Identifying Older Adult Participants With History of Falls Than Do the BESTest, Berg Balance Scale, or Timed Up and Go Test. J Geriatr Phys Ther. 2016;39(2):64-70. Available from: https:/ /insights.ovid.com/crossref?an $=00139143-201604000-00004$

12. Gajdosik RL, Vander Linden DW, McNair PJ, Williams AK, Riggin TJ. Effects of an eight-week stretching program on the passive-elastic properties and function of the calf muscles of older women. Clin Biomech (Bristol, Avon). 2005;20(9):973-83. Available from: http://linkinghub.elsevier.com/retrieve/ pii/S0268003305001233

13. Bakker JPJ, De Groot IJM, Beelen A, Lankhorst GJ. Predictive factors of cessation of ambulation in patients with Duchenne muscular dystrophy. Am J Phys Med Rehabil. 2002;81(12):906-12. Available from: http://www.ncbi.nlm. nih.gov/pubmed/12447089

14. Terada M, Kosik KB, McCann RS, Gribble PA. Diaphragm Contractility in Individuals with Chronic Ankle Instability. Med Sci Sports Exerc. 2016;48(10):2040-5. Available from: http://insights.ovid.com/crossref?an= 00005768-201610000-00022

15. Vandenbroucke JP, von Elm E, Altman DG, Gøtzsche PC, Mulrow CD, Pocock SJ, et al. Strengthening the Reporting of Observational Studies in Epidemiology (STROBE): explanation and elaboration. Int $\mathrm{J}$ Surg. 2014;12(12):1500-24. Available from: http://linkinghub.elsevier.com/retrieve / pii/S1743919114002131

16. Holt GR. Declaration of Helsinki-the world's document of conscience and responsibility. South Med J. 2014;107(7):407. Available from: http://sma.org/southern-medical-journal/article/declaration-of-helsinki-the -worlds-document-of-conscience-and-responsibility

17. World Medical Association Declaration of Helsinki. Ethical principles for medical research involving human subjects. J Am Coll Dent. 2014;81(3):14-8.

18. Löwhagen $\mathrm{O}$. Diagnosis of asthma - new theories. J Asthma. 2015;52(6):538-44. Available from: http://www.ncbi.nlm.nih.gov/pubmed/ 25478896

19. Garrow JS. Quetelet index as indicator of obesity. Lancet (London, England). 1986 May 24;1(8491):1219. Available from: http://www.ncbi.nlm.nih.gov/ pubmed/2871462

20. Gauthier AP, Lariviere M, Young N. Psychometric properties of the IPAQ: a validation study in a sample of northern Franco-Ontarians. J Phys Act Health. 2009;6 Suppl 1:S54-60. Available from: http://www.ncbi.nlm.nih.gov/ pubmed/19998850

21. Bennell KL, Talbot RC, Wajswelner H, Techovanich W, Kelly DH, Hall AJ. Intra-rater and inter-rater reliability of a weight-bearing lunge measure of ankle dorsiflexion. Aust J Physiother. 1998;44(3):175-80. Available from: http://www.ncbi.nlm.nih.gov/pubmed/11676731

22. Powden CJ. Hoch JM, Hoch MC. Reliability and minimal detectable change of the weight-bearing lunge test: A systematic review. Man Ther. 2015;20(4):524-32. Available from: https://linkinghub.elsevier.com/retrieve/ pii/S1356689X15000065

23. Langarika-Rocafort A, Emparanza JI Aramendi JF, Castellano J, Calleja-González J. Intra-rater reliability and agreement of various methods of measurement to assess dorsiflexion in the Weight Bearing Dorsiflexion Lunge Test (WBLT) among female athletes. Phys Ther Sport. 2017;23:37-44. Available from: https://linkinghub.elsevier.com/retrieve/pii/S1466853X16300554

24. Williams CM, Caserta AJ, Haines TP. The TiltMeter app is a novel and accurate measurement tool for the weight bearing lunge test. J Sci Med Sport. 2013;16(5):392-5. Available from: https://linkinghub.elsevier.com/retrieve/ pii/S1440244013000339

25. Romero Morales C, Calvo Lobo C, Rodríguez Sanz D, Sanz Corbalán I, Ruiz Ruiz B, López López D. The concurrent validity and reliability of the Leg Motion system for measuring ankle dorsiflexion range of motion in older adults. PeerJ. 2017;5:e2820. Available from: https:// peerj.com/articles/2820

26. Munteanu SE, Bassed AD. Effect of foot posture and inverted foot orthoses on hallux dorsiflexion. J Am Podiatr Med Assoc. 2006:96(1):32-7. Available from: http://www.ncbi.nlm.nih.gov/pubmed/16415281
27. Vulcano E Tracey JA, Myerson MS. Accurate Measurement of First Metatarsophalangeal Range of Motion in Patients With Hallux Rigidus. Foot Ankle Int. 2016;37(5):537-41. Available from: http://www.ncbi.nlm.nih.gov/ pubmed/26660863

28. Gómez-Pérez L, López-Martínez AE, Ruiz-Párraga GT. Psychometric Properties of the Spanish Version of the Tampa Scale for Kinesiophobia (TSK). J Pain. 2011;12(4):425-35. Available from: http://linkinghub.elsevier.com/ retrieve/pii/S1526590010006954

29. Chmielewski TL, Zeppieri G, Lentz TA, Tillman SM, Moser MW, Indelicato $\mathrm{PA}$, et al. Longitudinal changes in psychosocial factors and their association with knee pain and function after anterior cruciate ligament reconstruction. Phys Ther. 2011;91(9):1355-66. Available from: https://academic.oup.com/ ptj/article-lookup/doi/10.2522/ptj.20100277

30. Woby SR, Roach NK, Urmston M, Watson PJ. Psychometric properties of the TSK-11: A shortened version of the Tampa Scale for Kinesiophobia. Pain. 2005;117(1):137-44. Available from: http://www.ncbi.nlm.nih.gov/pubmed/ 16055269

31. George SZ, Valencia C, Beneciuk JM. A psychometric investigation of fear-avoidance model measures in patients with chronic low back pain. J Orthop Sports Phys Ther. 2010;40(4):197-205. Available from: http://www. jospt.org/doi/10.2519/jospt.2010.3298

32. Hapidou EG, O'Brien MA, Pierrynowski MR, de Las Heras E, Patel M, Patla T. Fear and Avoidance of Movement in People with Chronic Pain: Psychometric Properties of the 11-Item Tampa Scale for Kinesiophobia (TSK-11). Physiother Can. 2012 Jan;64(3):235-41.

33. Debouche S, Pitance L, Robert A, Liistro G, Reychler G. Reliability and Reproducibility of Chest Wall Expansion Measurement in Young Healthy Adults. J Manipulative Physiol Ther. 2016;39(6):443-9. Available from: http:// www.ncbi.nlm.nih.gov/pubmed/27346860

34. Irwig L, Groeneveld H, Becklake M. Relationship of lung function loss to level of initial function: correcting for measurement error using the reliability coefficient. J Epidemiol Community Health. 1988;42(4):383-9. Available from: http://www.ncbi.nlm.nih.gov/pubmed/3256581

35. Whittaker JL. Ultrasound imaging of the lateral abdominal wall muscles in individuals with lumbopelvic pain and signs of concurrent hypocapnia. Man Ther. 2008;13(5):404-10. Available from: http://linkinghub.elsevier.com/ retrieve/pii/S1356689X07000781

36. Calvo-Lobo $C$ Painceira-Villar $R$ López-López $D$, García-Paz $V$, Becerro-de-Bengoa-Vallejo R, Losa-Iglesias ME, et al. Tarsal Tunnel Mechanosensitivity Is Increased in Patients with Asthma: A Case-Control Study. J Clin Med. 2018;7(12):541. Available from: http://www.mdpi.com/ $2077-0383 / 7 / 12 / 541$

37. Terada M, Pietrosimone BG, Gribble PA. Therapeutic Interventions for Increasing Ankle Dorsiflexion After Ankle Sprain: A Systematic Review. J Athl Train. 2013;48(5):696-709. Available from: http://www.ncbi.nlm.nih.gov/ pubmed $/ 23914912$

38. Lopes AJ, Pinto Almeida V, Silveira Menezes SL, Guimarães FS. Balance Deficits are Correlated with Bronchial Obstruction Markers in Subjects with Asthma. J Phys Ther Sci. 2014;26(3):393-9. Available from: http://www.ncbi. nlm.nih.gov/pubmed/24707091 